\title{
Dynamics of Indirect Land-Use Change: Empirical Evidence from Brazil ${ }^{*}$
}

\author{
Saraly Andrade de Sá \\ Professorship of Environmental Policy and Economics, ETH Zurich \\ E-mail address: saraly.andrade@env.ethz.ch
}

Charles Palmer

Department of Geography and Environment, London School of Economics

\section{Salvatore Di Falco}

Department of Geography and Environment, London School of Economics

\begin{abstract}
The expansion of a given land use may affect deforestation directly if forests are cleared to free land for this use, or indirectly, via the displacement of other landuse activities from non-forest areas towards the forest frontier. Unlike direct land conversion, indirect land-use changes affecting deforestation are not immediately observable. They require the linking of changes occurring in different regions. This paper empirically estimates these indirect effects for the case of Brazil. It presents evidence of a positive relationship between sugarcane expansion in the south of the country and cattle ranching in the Amazon, suggesting that the former is indeed displacing the latter towards the forest frontier. This displacement effect is shown to be a dynamic process materializing over 10 to 15 years.
\end{abstract}

Keywords: Indirect land-use changes; Dynamic effects; Biofuels; Deforestation

*The authors would like to thank, without implicating, participants at the UQAM Economics Department 2012 Seminar, the London School of Economics 2011 Workshop on Land-Use Changes and Deforestation and at the AgroParisTech 2011 Workshop on "Perspectives de Recherches en Economie de la Biodiversité et de l'Environnement : Usage des Sols, Politiques Publiques Environnementales", as well as Michele Baggio, Julien Daubanes, Stefanie Engel, Mehdi Farsi, José Féres, Steve Gibbons, Ben Groom, Renger Herman van Nieuwkoop, Pierre Lasserre, Eustáquio Reis and Diana Weinhold. Financial support from the North-South Center at ETH Zurich is gratefully acknowledged. 


\section{Introduction}

In many tropical countries, agriculture often competes with standing forests for land. Hence, deforestation drivers can be generally understood as factors that increase the rents associated with agricultural expansion. Such factors include increased agricultural output prices, better agro-ecological conditions, lower input prices, better roads and infrastructure $^{1}$ as well as technological progress (see, for example, Kaimowitz and Angelsen, 1998; Angelsen and Kaimowitz, 1999; Barbier and Burgess, 2001). The role and the impact of these drivers have commonly been analyzed at the forest frontier, i.e. in regions where forest conversion to agriculture is observed. However, expanding agriculture may also cause indirect land-use changes. These have been shown to occur when agricultural activities displaced from one region drive expansion of the same land use in another region (Searchinger et al., 2008; Lapola et al., 2010; Arima et al., 2011). Indeed, diverting land from say pasture for cattle ranching to the production of sugarcane may result in higher prices of the latter. Holding demand constant, these higher prices may in turn provide farmers with incentives to create new pastures elsewhere, for example in forest areas, in order to meet supply shortfalls.

In this paper, we empirically assess the possible effects of sugarcane expansion in the Brazilian state of São Paulo on forest conversion decisions in the country's Amazon region, via a displacement of cattle ranching activities. Departing from recent research that focused on the spatial measurement of displacement of pastures to the Brazilian Amazon (e.g. Barona et al., 2010; Lapola et al., 2010; Arima et al., 2011), we focus on the temporal aspect of displacement. Specifically, we apply the Arellano-Bover (1995)/Blundell-Bond (1998) System-GMM estimator to a panel dataset collected in Brazil, spanning a 36 year period from 1970 to 2006. In doing so, we present unique evidence for the displacement of pastures from São Paulo state to the Amazon, which is shown to be a dynamic process that only materializes after around 10 to 15 years.

Andrade de Sá et al. (2012) derive the formal conditions under which such a displacement effect may occur. They show that a necessary condition for displacement to take place is that the output of the activity being displaced faces a relatively inelastic demand, which might be the case, for instance, if the displaced crop is a staple food produced and consumed locally, or if the country is a major producer and exporter such that its supply

\footnotetext{
${ }^{1}$ The impact of building new roads in forest areas is subject to some debate. Many scholars expect that new roads lead to more deforestation by decreasing transport costs thus increasing the profitability of agricultural activities in forest areas. But if new roads lead to a short-term increase in deforestation, this effect could be reversed in the long-term. Since activities and people tend to concentrate around roads, this may lead to a lower overall spread of deforestation (see Weinhold and Reis, 2008).
} 
affects international prices. This effect applies to the expansion of any land use including agricultural commodities that could be used either for the production of food or biofuels (see Gallagher, 2008). Focusing on the expansion of the area of land under sugarcane in Brazil for the production of ethanol, we join the debate about the desirability of biofuels as oil substitutes. From the perspective of biofuels providing carbon savings vis-à-vis fossil fuels (e.g. Feng et al., 2010; Righelato and Spracklen, 2007), any potential impact on deforestation will clearly reduce their attractiveness. The reduction in greenhouse gas emissions from oil substitution may be, at least partially, compensated by the decrease in carbon stocks resulting from induced forest conversion.

In Brazil, increased ethanol production resulted in a significant expansion of sugarcane acreage. Indeed, from 1975 to 2008, land allocated to sugarcane increased from 1.9 to 8.9 million hectares such that currently, 'sugarcane and its derivatives are the second main primary power source of the national energy matrix, and the domestic ethanol consumption is already superior to the one of gasoline' (MAPA, 2009). Nevertheless, there are growing concerns about the possibility of sugarcane expansion provoking indirect land-use changes leading to deforestation in the Amazon. For example, a recent report by the World Bank (2011) notes that about two-thirds of the area into which sugarcane expanded came from converting pasture land with the remainder coming from substituting other crops $(32 \%)$ and from converting natural vegetation $(2 \%)$. Yet, despite rapid gains in productivity in both sugarcane and pastures, which reduced the indirect effects of agricultural land expansion, 'the resulting higher price of land has probably put pressure on pasture expansion further north to the cerrado and the Amazon biome' (World Bank, 2011: 19).

This paper joins an emerging body of research on land-use displacement in Brazil. Nassar et al.'s (2008) descriptive statistics for the period 2005-2008 suggest very low indirect land-use changes associated with sugarcane expansion, with 0.08 hectares of deforested land for each additional sugarcane hectare. More recently, de Souza Ferreira Filho and Horridge (2011) investigate the same issue but using a computable general equilibrium model calibrated with Brazilian data from 2005. According to their simulations over the period 2008-2020, 'each extra sugarcane hectare [will be] associated with 0.14 hectares fall in unused [mainly naturally forested] land and with 0.47 hectares fall in pasture', which is higher than the estimates from Nassar et al. (2010). Utilizing a suite of models, Lapola et al. (2010) also simulate possible indirect land-use changes resulting from the expansion of both sugarcane ethanol and soybean biodiesel in Brazil and estimate the potential carbon balance. They find that such changes are likely to offset the carbon savings from biofuels.

None of these studies, however, attempted to systematically test for the presence and 
size of the effect arising from the displacement of cattle ranching by the expansion of sugarcane production, i.e. using econometric methods and historical land use data. Two recent papers by Barona et al. (2010) and Arima et al. (2011) are among the first attempts, to our knowledge, to statistically test for the displacement of soybean and cattle pastures. Barona et al. (2010) use Geographic Information System (GIS) methods and municipality-level statistics on agricultural and deforested areas across the Legal Amazon from 2000 to 2006 to examine the spatial patterns and statistical relationships between deforestation and changes in pasture and soybean areas. Consistent with previous research, their results show that deforestation is predominantly a result of expanding pasture. Utilizing three statistical models (one ordinary least squares regression, and two panel analyses), Arima et al. (2011) show that deforestation in the Legal Amazon between 2003 and 2008 is strongly related to soy expansion in its settled agricultural areas, to the south and east.

Our contribution to the literature is thus to focus solely on the displacement of cattle ranching from the non-Amazon regions, specifically the state of São Paulo, and on the dynamics of displacement over a much longer period of time. Moreover, in contrast to Barona et al. (2010) and Arima et al. (2011) we concentrate on establishing empirical evidence for a linkage between the expansion of sugarcane outside the Amazon and cattle ranching in the Amazon.

This paper also naturally relates to the literature on deforestation drivers in general, and in the Brazilian Amazon in particular. Pfaff (1999), Chomitz and Thomas (2003), and Andersen et al. (2002) highlight the role played by roads, cattle ranching, soy production and credit facilities, among other factors as key drivers of deforestation. We also consider these factors but depart from previous studies by explicitly considering sugarcane expansion in non-Amazon regions as an additional potential factor of forest conversion. Furthermore, our analysis emphasizes the dynamic, rather than the spatial, aspect of displacement and forest conversion. Indeed, a key insight from the deforestation literature is that forest conversion and land-use changes are phenomena that exhibit spatial patterns. Not only does forest conversion tend to concentrate around particular areas, such as roads and rivers, for instance, but there is also evidence that forest areas located close to conversion regions are under higher pressure (Pfaff, 1999; Chomitz and Thomas, 2003; Andersen et al., 2002). In a similar vein, certain agro-ecological conditions, infrastructure and zoning rules may result in a concentration of crops in some regions. ${ }^{2}$ This result has

\footnotetext{
${ }^{2}$ For instance, Brazil's national agronomy institute, EMBRAPA, has developed agro-ecological zoning for different crops, determining the best production regions (see www.embrapa.br). In the case of sugarcane, this zoning has resulted in the banning of production in the Legal Amazon (EMBRAPA, 2009).
} 
led to the increased use of spatial methods that can control for spatial auto-correlation in forest conversion decisions.

Spatial methods are appropriate for the analysis of neighboring/contiguity effects (see Anselin, 2009). However, they are not suited to our purpose of exploring possible links between the expansion of sugarcane in the south of Brazil with forest conversion in the Amazon. The former is situated thousands of kilometers from the latter (see Figure A.1 in Appendix A). This distance implies that the displacement effect can take a number of different spatial patterns, which are not observable in the data. On the one hand, displaced cattle ranching from the south may have gradually relocated further north. But, on the other, it is also possible that ranchers in the south decided to migrate straight to the Amazon region. Using spatial methods would require assuming a determined structure of displacement, which, if incorrect may lead to misleading results. Yet, focusing on the dynamic aspect of displacement may provide insights on how it takes place. For instance, if the effects of sugarcane expansion only materialize after some period of time then this could imply that cattle ranching has been displaced gradually. On the contrary, strong short-run effects of sugarcane expansion on forest conversion could imply that displaced ranchers moved relatively quickly and directly to the forest frontier.

Restricting attention to the dynamics of the displacement process, we apply the Arellano-Bover (1995)/Blundell-Bond (1998) System-GMM estimator to a panel dataset of Brazilian land uses, along with a number of other selected variables, which cover the period 1970-2006. In dealing with potential endogeneity among the explanatory variables, this estimator ensures that efficient parameters' estimates are obtained. Additionally, it supports the use of lagged values of the explanatory variables, which allows us to investigate their long-run effects on forest conversion. Our results suggest a positive relationship between sugarcane expansion and deforestation in the Amazon. This relationship is derived from the impact of cattle ranching on forest conversion being sensitive to the levels of sugarcane acreage in the state of São Paulo. It holds even after controlling for other factors of deforestation. This result is consistent with a displacement effect whereby cattle ranching is 'pushed' further north, all the way to the Amazon, by the expansion of sugarcane acreage in the Center-South region of Brazil (Região Centro-Sul). The process is shown to be dynamic; the data indicate that a 10 to 15 year period was necessary for the effect to materialize.

The remainder of the paper is organized as follows. Section 2 provides a brief background of the Brazilian ethanol market and the country's deforestation history. Section 3 introduces the conceptual framework underlying the estimated model while data used for the empirical analysis are presented in Section 4. Section 5 presents the empirical results 
and Section 6 provides some further discussion of the results before concluding.

\section{Background}

This section presents background information on the development and current status of the Brazilian ethanol market and on deforestation in the Brazilian Amazon. Our analysis is motivated by Brazil for a number of reasons. First, Brazil is currently the second largest global ethanol producer (MAPA, 2009), with large-scale production occurring for more than 20 years. This provides us with a sufficiently long time frame for investigating the dynamics of indirect land-use changes. Second, it hosts the largest part of the Amazon rainforest, which has registered relatively high levels of deforestation in the past. Relatively good, long-term data on land use are available for Brazil unlike many tropical forest countries. Additionally, Brazil is also a major global producer of several other agricultural commodities, in particular soybean and beef (World Bank, 2011). This is an important feature as it translates into many activities potentially being displaced by the expansion of sugarcane production. Finally, the main sugarcane production area is located far from the Amazon forest frontier. Since the notion of indirect land use changes presupposes that the expanding land use is displacing other activities towards a different region, Brazil is an ideal laboratory for examining the possibility of these in the empirical record. ${ }^{3}$

\subsection{The Brazilian ethanol market}

Ethanol production in Brazil began in the late 1970s with the beginning of the PróAlcool program. The aim of the program was to lower the country's dependence on imported oil via public intervention. To stimulate production, PróAlcool was used to distribute subsidies to expand sugarcane production, construct distilleries and conduct public research on, for example, new sugarcane varieties. On the demand side, the government opted for fuel blending mandates, e.g. E85, which created domestic demand for ethanol. Although never officially terminated, the program's subsidies were gradually withdrawn from 1998 onward and, to date, none remain. This period was nevertheless sufficiently long to develop a large, national ethanol market.

The new market resulted in the area under sugarcane increasing from 1.9 to 8.9 million

\footnotetext{
${ }^{3}$ This rules out Indonesia as a case study area, for instance, since palm oil plantations have long been planted directly in newly-deforested land (see, for example, Wakker, 2005. Available at http://www.foe.co.uk/resource/reports.). We also note that sugarcane expansion in Brazil has reportedly driven deforestation of the country's Atlantic forest (See: http://www.biodiversityhotspots.org). Yet, this is a direct land competition effect that we do not consider in this paper.
} 
hectares from 1975 to 2008. Associated production rose from around 89 to 589 million tons (MAPA, 2010). ${ }^{4}$ Most of this expansion, in both ethanol and sugarcane production, occurred in the Center-South region of Brazil, in particular São Paulo state. Approximately $70 \%$ of Brazilian sugarcane is currently produced in that state alone (UNICA, 2009). ${ }^{5}$ Ethanol production increased from about 0.6 million cubic meters in 1975 , to 27.5 million cubic meters in 2009. ${ }^{6}$

These huge increases in sugarcane acreage and ethanol production are both expected to continue apace, driven by national and international demand. In the national market, demand further increased after the introduction of flex-fuel cars, which are able to run with any blend of ethanol and gasoline. In 2008, 1.2 million of these vehicles were produced in the country. ${ }^{7}$ Regarding international demand, Brazil began exporting ethanol in 1989, although exports only reached significant amounts after 2004 (MAPA, 2010). By 2009, around 3.3 million cubic meters of Brazilian ethanol were exported (ibid). The country expects exports to continue to rise with the decision of many European Union countries to introduce their own blending mandates in the coming years (REN, 2009).

\subsection{Deforestation in the Brazilian Amazon}

Brazil hosts around $60 \%$ of the Amazon rainforest. It corresponds to the North region of the country (Região Norte) and includes the states of Acre, Amapá, Amazonas, Mato Grosso, Pará, Rondônia, Roraima and Tocantins, with an estimated surface area of 3.6 million square kilometers. Note that states are composed of numerous counties ( $m u$ nicipios), the third tier of government. The Legal Amazon, which is a larger area than the North region, is a geopolitical construction established by public authorities in 1966 for planning purposes (Andersen et al., 2002). Additional to the states mentioned above, it includes parts of Maranhão and Mato Grosso raising the total area to 5.2 million square kilometers, which corresponds to about $60 \%$ of Brazilian territory.

In the 1960s, public credit and subsidies to agriculture coupled with road network development $^{8}$ fostered migration to the Amazon (Rudel, 2005). Government programs

\footnotetext{
${ }^{4}$ Sugarcane production can also be measured in terms of Total Reducing Sugar (TRS) which is the final refined product that can be transformed into either sugar or ethanol. During the 2009/2010 season, of the total amount of TRS produced, $57 \%$ were devoted to ethanol. In 1975, the ethanol share was only $13 \%$.

${ }^{5}$ Data available at http://www.unica.com.br/dadosCotacao/estatistica/.

${ }^{6} 1$ cubic meter is exactly equivalent to 1000 liters.

${ }^{7}$ Data available at http://www.unica.com.br/dadosCotacao/estatistica/.

${ }^{8}$ Important road projects in the Legal Amazon began mainly after the shift of the federal capital from Rio de Janeiro to Brasilia, in 1960. These included the construction of the Belém-Brasilia road, the Transamazônica, the Cuiabá-Santarém road and the Cuiabá-Porto Velho road in the 1970s (Andersen
} 


\begin{tabular}{|c|c|c|c|c|c|c|c|c|c|c|c|}
\hline States/Year & 2000 & 2001 & 2002 & 2003 & 2004 & 2005 & 2006 & 2007 & 2008 & 2009 & 2010 \\
\hline Acre & 547 & 419 & 883 & 1078 & 728 & 592 & 398 & 184 & 254 & 167 & 273 \\
\hline Amazonas & 612 & 634 & 885 & 1558 & 1232 & 775 & 788 & 610 & 604 & 405 & 474 \\
\hline Amapá & & 7 & 0 & 25 & 46 & 33 & 30 & 39 & 100 & 70 & 0 \\
\hline Maranhão & 1065 & 958 & 1085 & 993 & 755 & 922 & 674 & 631 & 1271 & 828 & 679 \\
\hline Mato Grosso & 6369 & 7703 & 7892 & 10405 & 11814 & 7145 & 4333 & 2678 & 3258 & 1049 & 828 \\
\hline Pará & 6671 & 5237 & 7510 & 7145 & 8870 & 5899 & 5659 & 5526 & 5607 & 4281 & 3710 \\
\hline Rondônia & 2465 & 2673 & 3099 & 3597 & 3858 & 3244 & 2049 & 1611 & 1136 & 482 & 427 \\
\hline Roraima & 253 & 345 & 84 & 439 & 311 & 133 & 231 & 309 & 574 & 121 & 0 \\
\hline Tocantins & 244 & 189 & 212 & 156 & 158 & 271 & 124 & 63 & 107 & 61 & 60 \\
\hline Legal Amazon & 18226 & 18165 & 21651 & 25396 & 27772 & 19014 & 14286 & 11651 & 12911 & 7464 & 6451 \\
\hline
\end{tabular}

Table 1: Deforestation in Legal Amazon States (square kilometers, 2000-2010)

promoting the occupation of the region were mainly thought of as means to develop the area and release demographic pressure from other parts of the country (Pfaff, 1999). The progressive occupation of the Legal Amazon has gradually changed deforestation patterns with cattle ranching replacing timber exploitation as the main source of rents from forest conversion from the 1970s onwards (Andersen et al., 2002). Annual forest loss in the Legal Amazon remained relatively stable at around 20,000 square kilometers in the 1970s and 1980s before ranging from 10,000 to 30,000 square kilometers during the 1990s. Table 1 presents annual forest loss in the previous decade. ${ }^{9}$ Despite a sharp decline from the beginning to the end of the decade, forest loss in 2010 at approximately 6,450 square kilometers is comparable to observed amounts of deforestation in Indonesia (FAO, 2010).

\section{The conceptual framework}

We begin by following Pfaff's (1999) land-use model which allows for many possible determinants of deforestation. The underlying theory behind this model is that farmers allocate land between alternative uses in order to maximize their returns. For the sake of simplicity, it is assumed that at the forest frontier farmers have the choice between two land uses $l=\{c, u\}$, where $c$ denotes cleared land put under agricultural production and $u$ denotes uncleared land (i.e. where forests are kept standing). Therefore, at time $t$, a plot of land $j$ within county $i$ is allocated to one of the alternative uses so as to maximize profit:

$$
\max \Pi_{i j t}^{l}=P_{i j t}^{l} Q_{i j t}^{l}\left(I_{i j t}^{l}\right)-W_{i j t}^{l} I_{i j t}^{l},
$$

et al., 2002). In particular, the Belém-Brasilia road connected the Legal Amazon with the rest of the country, reducing dependence on rivers as a source of transportation (ibid).

${ }^{9}$ Data from INPE - Brazilian National Institute of Spatial Research, available at http://www.obt.inpe.br/prodes/prodes_1988_2010.htm. Values for 2010 are estimates. 
where $P_{i j t}^{l}$ are the plot level prices for the vector of alternative outputs from any given land use, $Q_{i j t}^{l}$ is the vector of outputs, $I_{i j t}^{l}$ is the vector of inputs used, and $W_{i j t}^{l}$ are plot-level prices for the vector of inputs.

The $P_{i j t}$ and $W_{i j t}$ plot-level output and input prices may not be observable in practice. However, these prices result from the realization of equilibria in broader markets, which are jointly determined by both local and non-local (e.g. regional, national, international) conditions. Therefore, we can consider $P_{i j t}$ and $W_{i j t}$ to be functions of both local and non-local parameters. For instance, output prices may depend on local, national and international demand shifters such as population and transport costs. For the same reasons, input prices at the plot level depend not only on local market equilibria but also on the demand for these inputs in other regions. Therefore, we depart from Pfaff $(1999)^{10}$ by considering

$$
P_{i j t}=P_{i j t}\left(X_{i t}, Z_{k t}\right)
$$

and

$$
W_{i j t}=W_{i j t}\left(X_{i t}, Z_{k t}\right)
$$

where $X_{i t}$ is a vector of parameters defining local conditions at the forest frontier, i.e. in the $i=\{1, \ldots, n\}$ forest counties, (e.g. road infrastructure, soil fertility, population, credit received by producers) while $Z_{k t}$ is a vector of parameters corresponding to the $k=$ $\{n+1, \ldots, n+m\}$ counties that are not part of the standing forest area. This distinction of counties into forest and non-forest regions will serve our goal of testing whether land-use changes in non-forest regions may affect incentives to clear forest in the Amazon.

Assuming privately optimal input decisions, (1) yields $I_{i j t}^{l *}=\arg \max \Pi_{i j t}^{l}=I_{i j t}^{l *}\left(P_{i j t}^{l}, W_{i j t}^{l}\right)$. Combining this with (2) and (3), we define a value function $V_{i j t}^{l} \equiv \Pi_{i j t}^{l *} \equiv V_{i j t}^{l}\left(X_{i t}, Z_{k t}\right)$. Thus, normalizing a plot area to unity, total forest conversion in a given county $i$, at a given time $t$ is

$$
y_{i t}=\Sigma_{j} \amalg_{\left\{V_{i j t}^{c}>V_{i j t}^{u}\right\}},
$$

where $\mathbb{I}_{\left\{V_{i j t}^{c}>V_{i j t}^{u}\right\}}$ is an indicator function.

Up to this point, we have assumed a static framework to render clear the role that changing conditions in non-forest areas play in determining forest conversion decisions. However, in practice, deforestation is a dynamic process in which changes to key factors occurring in previous periods are likely to have affected current conditions and, therefore, current decisions. For instance, areas that were previously partially cleared may be easier to access and deforest today. In the same vein, public policies such as subsidized credit

\footnotetext{
${ }^{10} \mathrm{As}$ it is traditional in the literature on deforestation drivers, Pfaff (1999) only considers local parameters and parameters in neighboring counties.
} 
lines or colonization programs may take a few years to impact deforestation. To account for these, we introduce lagged values of our parameters in the estimation. Thus, from (4) we derive the following linearized expression to be estimated:

$$
y_{i t}=\hat{y}_{i t}+\epsilon_{i t}
$$

where

$$
\hat{y}_{i t}=\beta_{0}+\beta_{1} y_{i, t-s}+\beta_{2} X_{i, t}+\beta_{3} Z_{k, t}+\beta_{4} Z_{k, t-s}+\beta_{5} X_{i, t} Z_{k, t}+\beta_{6} X_{i, t} Z_{k, t-s}+\mu_{i},
$$

is the estimated amount of forest conversion at time $t$ in county $i, s \geq 1$ is the number of lags and $\mu_{i}$ are county-specific unobservable fixed effects.

Despite the fact that equations (5) and (6) imply a linear functional relationship, obtaining consistent parameter estimates remains challenging for mainly two reasons. First, we consider our dependent variable to be dynamic in the sense that it depends on past realizations. Second, a number of the explanatory variables in $X_{i t}$ and $Z_{k t}$ are unlikely to be strictly exogenous. Taken together, these suggest that obtaining consistent parameter estimates necessitates the use of a generalized method of moments (GMM) dynamic estimator. More precisely, we use the Arellano-Bover (1995)/Blundell-Bond (1998) System-GMM estimator, which implies a transformation of the regressors, usually by taking differences, and the use of the lagged values of the dependent variable as instruments as well as initial conditions in the levels of the regressors.

At this point, one may ask why a simultaneous equations approach, i.e. jointly estimating the whole system of output supply and demand for inputs in forest areas, is not employed. We acknowledge that this approach is also valid. However, several reasons led us not to opt for it. First, since equation (4) is defined as a sum of indicator functions, the cross properties arising in a conventional supply/demand system would have been lost through the imposition of restrictions on the parameters of equation (6). Therefore, the simultaneous equations approach would not have enhanced the estimation's results. Moreover, as stated earlier, we focus here on the dynamic aspect of the displacement effect. Doing so using a simultaneous equations approach would have been less tractable than the approach adopted in our analysis. 


\section{Data sources and variables description}

For our empirical analysis we constructed a panel data set using secondary data for all of Brazil's counties for the years 1970, 1975, 1980, 1985, 1995-96 and 2006. Since the structure of Brazilian counties has changed during this time span, we aggregated the municipal data into 3,652 Minimum Comparable Areas $^{11}$ (MCAs), 258 of which are within the Legal Amazon. These 258 MCAs constitute our units of observation, $i$.

While the Brazilian National Institute of Geography and Statistics (Instituto Brasileiro de Geografia e Estatística, IBGE) datasets are the only reliable source of information available for our purposes, they present some limitations. First, there may be a lack of precision with regards to the estimates of deforestation in cases where producers failed to make a direct declaration. This resulted in estimates having to be obtained indirectly from statements regarding land use in the various agricultural/cattle ranching properties. Also, the IBGE Census, in principle, includes all these properties in the Legal Amazon but fails to give information relating to publicly owned or unclaimed land. Deforestation, therefore, may be underestimated (Margulis, 2004). Additionally, the level of aggregation (MCA) may have led to imprecisions in a number of measurements such as the distance to the state capital and road density. Finally, the gaps between censuses (five to ten years) can also lead to a loss of important dynamic information.

Tables B.1 and C.1 (see Appendices B and C), respectively, present a description of the main variables used in the analysis and offer some descriptive statistics.

\footnotetext{
${ }^{11}$ The list of the Brazilian MCAs from 1970 to 2005 was provided by the Brazilian Institute of Applied Economic Research (Instituto de Pesquisa Econômica Aplicada, IPEA).
} 


\subsection{Land use and land cover}

Land use data were obtained from IBGE's agricultural censuses undertaken in 1970, 1975, 1980, 1985, 1995-1996 ${ }^{12}$ and 2006. They include data on total land cleared, ${ }^{13}$ hectares planted with sugarcane, soy and pasture, as well as number of cattle heads. The motivation to include pasture, cattle heads and soy as explanatory variables is derived from previous studies investigating forest conversion in the Brazilian Amazon.

The inclusion of number of hectares of sugarcane produced in the state of São Paulo merits discussion. The main hypothesis we are testing is whether sugarcane expansion in the Center-South region is displacing cattle ranching towards the Amazon forest frontier thus impacting on levels of deforestation. We therefore include in our analysis hectares allocated to sugarcane in São Paulo state, which as previously noted accounts for a clear majority of Brazilian sugarcane and ethanol production. Additionally, we interact sugarcane hectares with cattle heads in the Amazon MCAs using both the same year values and sugarcane acreage lags. The latter take into account the possibility of displacement taking a longer period of time to affect land-use change in the Amazon given the distance between São Paulo and the Amazon MCAs.

\subsection{Socioeconomic data}

Data on the counties' GDP, population and rural credit were obtained through IPEA. ${ }^{14}$ We used data on counties' resident populations to compute GDP per capita and population density variables for our units of observation.

Regarding roads, we were only able to obtain state level data using the Anuários Estatisticos do Brasil, which were provided by IBGE. We used the total values, which included municipal, state and federal roads, both paved and unpaved. To obtain average

\footnotetext{
${ }^{12}$ For the 1996 census, IBGE changed the reference as well as the data collection period. Data were collected in August 1996 instead of January as in previous censuses. Thus, officially, these data are not strictly comparable to the those collected both in the previous and following censuses. Some scholars have argued that the apparent decrease in production and rural employment in 1996, when compared to the 1985 census, may have been due to this change in the data collection period. Since August corresponds to the end of the agricultural season in Brazil, most precarious establishments - i.e. temporary farms occupied by squatters, sharecroppers and land tenants that are only active during the agricultural season - may not have been properly identified (Helfand and Brunstein, 1999, cited in Andersen et al, 2002). However, some macroeconomic changes during the period 1985-1996, including the elimination of most agricultural subsidies in the late 1980s, may also partly explain these results (Andersen et al., 2002). Additionally, so long as the eventual undercount can be assumed to be randomly distributed among municipalities, it should not affect our econometric analysis (ibid). Following this line of reasoning, we opted to include the 1996 data in our analysis.

${ }^{13}$ Cleared land is defined as the sum of land under perennial crops, annual crops, planted pasture, planted forests as well as long and short fallow land.

${ }^{14}$ Available at www.ipeadata.gov.br.
} 
MCA values we multiplied the state-level total kilometers of roads by the proportion of each MCA area relative to the state area.

\subsection{Geo-ecological data}

Climate and soil characteristics have been shown to play a role in forest conversion. For instance, according to Chomitz and Thomas (2003) regions with higher rainfall are less appropriate for agriculture and thus less prone to forest conversion. We therefore include average annual precipitation for each MCA. The precipitation variable is also squared and included in the analysis so as to take into consideration that after a given positive threshold, precipitation lowers agricultural productivity. Finally, we obtained data on the soil fertility of each county through shapefiles made available by IBGE. After aggregating the information to the MCA level, we classified the different MCAs according to very low, low, medium, medium-high and high soil fertility.

\section{Empirical results}

The dynamic equation presented in (5) and (6) is estimated using the Arellano-Bover (1995)/ Blundell-Bond (1998) System-GMM estimator, and the two-step procedure is applied. ${ }^{15}$ Since the latter is known to yield biased standard errors we use the biasedcorrected robust variance estimator developed by Windmeijer (2005), known as the WCrobust estimator. This allows us to obtain unbiased standard errors that also allow for heteroskedasticity in the errors. ${ }^{16}$

The estimation results are reported in Table 2. The dependent variable in all specifications is 'hectares of cleared land in the Legal Amazon MCAs'. We begin with a simple regression where only cattle heads, sugarcane acreage in the state of São Paulo (current and lagged values) and a lagged-dependent variable are used as regressors (models 1 and 2 ). We then gradually include additional explanatory variables. In particular, in models 3 to 5 , we sequentially include interaction terms between current values of cattle heads in the forested counties and current and lagged values of sugarcane acreage in São Paulo state. Note that, despite being very small the coefficients associated with these interaction terms remain consistent. With the exception of the coefficient associated with the

\footnotetext{
${ }^{15}$ The regressions were also undertaken using the Difference-GMM estimator of Arellano and Bond (1991). Results were similar but less consistent across specifications. This can be explained by the fact that the System-GMM estimator, by using additional moment conditions, is a more precise estimator and has better finite sample properties (Cameron and Trivedi, 2009).

${ }^{16}$ The system GMM is implemented using stata 11 xtdpdsys command (StataCorp., 2009).
} 
interaction between cattle heads and sugarcane acreage lagged once, the coefficients are statistically significant. We further explore these coefficients in what follows. Finally, in models 6 and 7 , we include additional explanatory variables.

Cattle heads, hectares allocated to planted pasture and soy, as well as road density are treated as endogenous regressors because they are likely to react to other determinants of forest conversion and land-use decisions. For instance, the decision to construct a new road or extend a preexisting one, especially when taken by state and/or municipal authorities, may be responding to local demand in already-cleared areas rather than resulting from exogenous decisions to 'conquer' new territories (see Pfaff, 1999; Andersen et al., 2002). The remaining explanatory variables (hectares of natural pasture, GDP per capita, population density, average credit granted to farmers, distance to the state capital and to São Paulo, soil fertility, precipitations and agricultural GDP in São Paulo) are considered exogenous. Table 2 also reports the Wald $\chi^{2}$ statistic of overall significance for each of the specifications. According to this statistic, model 6 has the highest overall explanatory power. We will therefore use it as our reference point.

In the Arellano-Bover/Blundell-Bond approach, the error term $\epsilon_{i t}$ is assumed to be serially uncorrelated, which implies that there should be no evidence of second-order correlation in $\Delta \epsilon_{i t}$. This condition is essential to obtain consistent parameter estimates. Tests for second-order correlation are provided in Table 3. The null hypothesis of no serial autocorrelation is not rejected in any of the different specifications used. This implies that the assumption of serially uncorrelated $\epsilon_{i t}$ is supported by the data. ${ }^{17}$

In the following, we discuss the role of sugarcane expansion in driving land-use changes in the Brazilian Amazon before discussing the role of the more traditionally-considered drivers of deforestation.

\subsection{The role of sugarcane}

In order to test whether sugarcane expansion in the state of São Paulo affects forest conversion decisions in the Amazon we include current and lagged values of sugarcane acreage in the São Paulo area as regressors, and interact them with the current level of cattle heads

\footnotetext{
${ }^{17}$ An additional condition for the System-GMM estimator to produce consistent estimates is to use valid moment conditions. Although there is no method to test if the moment conditions from an exactly identified model are valid, one can test whether the over-identifying moment conditions are valid by performing the Sargan test of over-identifying conditions, as discussed in Arellano and Bond (1991). However, since we use robust standard errors that deal with potential heteroskedasticity in the data, the Sargan test becomes baseless. We nevertheless perform it on non-robust versions of all the specifications and the null hypothesis of valid over-identifying restrictions is not rejected for model 6 and is rejected only at the $10 \%$ level for model 7 .
} 


\begin{tabular}{|c|c|c|c|c|c|c|c|}
\hline & model 1 & model 2 & model 3 & model 4 & model 5 & model 6 & model 7 \\
\hline \multirow[t]{2}{*}{ L.cleared } & $0.930^{* * *}$ & $0.983^{* * *}$ & $0.790^{* * *}$ & $0.828^{* * *}$ & $0.752^{* * *}$ & $0.568^{* * *}$ & $0.531^{* * *}$ \\
\hline & $(0.000)$ & $(0.000)$ & $(0.000)$ & $(0.000)$ & $(0.000)$ & $(0.000)$ & $(0.000)$ \\
\hline \multirow[t]{2}{*}{ L2.cleared } & & $-0.158^{* * *}$ & $-0.113^{* * *}$ & $-0.105^{*}$ & 0.101 & $-0.157^{* * *}$ & $-0.165^{* * *}$ \\
\hline & & $(0.000)$ & $(0.000)$ & $(0.032)$ & $(0.181)$ & $(0.000)$ & $(0.000)$ \\
\hline \multirow[t]{2}{*}{ cattle } & $0.298 * * *$ & $0.332 * * *$ & $1.211^{* * *}$ & $1.456^{* * *}$ & $1.898 * * *$ & $1.490 * * *$ & $1.402 * * *$ \\
\hline & $(0.000)$ & $(0.000)$ & $(0.000)$ & $(0.000)$ & $(0.000)$ & $(0.000)$ & $(0.000)$ \\
\hline \multirow[t]{2}{*}{ SPsgen } & -0.0116 & -0.0238 & 0.0628 & 0.0867 & $0.0881 *$ & $0.0806 * *$ & 0.0421 \\
\hline & $(0.766)$ & $(0.571)$ & $(0.071)$ & $(0.056)$ & $(0.037)$ & $(0.002)$ & $(0.367)$ \\
\hline \multirow[t]{2}{*}{ L.SPsgen } & -0.0229 & 0.00202 & $-0.157^{*}$ & $-0.187^{*}$ & $-0.137^{*}$ & $-0.120 * *$ & -0.0576 \\
\hline & $(0.739)$ & $(0.978)$ & $(0.012)$ & $(0.017)$ & $(0.038)$ & $(0.003)$ & $(0.346)$ \\
\hline \multirow[t]{2}{*}{ L2.SPsgen } & 0.0435 & 0.0330 & $0.113^{* *}$ & $0.110^{* *}$ & 0.0367 & 0.0212 & \\
\hline & $(0.207)$ & $(0.363)$ & $(0.001)$ & $(0.005)$ & $(0.307)$ & $(0.202)$ & \\
\hline \multirow[t]{2}{*}{ cattleSPsgcn } & & & $-0.000000237^{* * *}$ & $-0.00000154^{*}$ & $-0.00000156^{*}$ & $-0.00000168 * * *$ & $-0.00000146 * * *$ \\
\hline & & & $(0.000)$ & $(0.013)$ & $(0.027)$ & $(0.000)$ & $(0.000)$ \\
\hline \multirow[t]{2}{*}{ cattleLSPsgen } & & & & $0.00000171^{*}$ & 0.0000000383 & 0.000000301 & -0.000000122 \\
\hline & & & & $(0.036)$ & $(0.967)$ & $(0.338)$ & $(0.741)$ \\
\hline \multirow[t]{2}{*}{ cattleL2SPsgcn } & & & & & $0.00000219 * * *$ & $0.00000212^{* * *}$ & $0.00000230 * * *$ \\
\hline & & & & & $(0.000)$ & $(0.000)$ & $(0.000)$ \\
\hline \multirow[t]{2}{*}{ soya } & & & & & & 0.139 & -0.119 \\
\hline & & & & & & $(0.508)$ & $(0.680)$ \\
\hline \multirow[t]{2}{*}{ plpast } & & & & & & $0.634^{* * *}$ & $0.807^{* * *}$ \\
\hline & & & & & & $(0.000)$ & $(0.000)$ \\
\hline \multirow[t]{2}{*}{ road_dens } & & & & & & $295693.2^{*}$ & $1064821.5^{*}$ \\
\hline & & & & & & $(0.040)$ & $(0.013)$ \\
\hline \multirow[t]{2}{*}{ natpast } & & & & & & 0.0403 & $0.0763^{*}$ \\
\hline & & & & & & $(0.117)$ & $(0.010)$ \\
\hline \multirow[t]{2}{*}{ gdpcap } & & & & & & -0.793 & 0.481 \\
\hline & & & & & & $(0.069)$ & $(0.675)$ \\
\hline \multirow[t]{2}{*}{ pop_dens } & & & & & & 4.210 & -0.813 \\
\hline & & & & & & $(0.133)$ & $(0.975)$ \\
\hline \multirow[t]{2}{*}{ credit } & & & & & & $0.00000490^{* *}$ & $0.00000556^{* *}$ \\
\hline & & & & & & $(0.001)$ & $(0.002)$ \\
\hline \multirow[t]{2}{*}{ dist_state_cap } & & & & & & $-403.9^{*}$ & $-933.7^{*}$ \\
\hline & & & & & & $(0.020)$ & $(0.018)$ \\
\hline \multirow[t]{2}{*}{ fertility } & & & & & & $108605.4^{* * *}$ & $170828.3^{* * *}$ \\
\hline & & & & & & $(0.000)$ & $(0.000)$ \\
\hline \multirow[t]{2}{*}{ gdpagric_SP } & & & & & & & 0.000193 \\
\hline & & & & & & & $(0.801)$ \\
\hline \multirow[t]{2}{*}{ precip } & & & & & & & -529.8 \\
\hline & & & & & & & $(0.523)$ \\
\hline \multirow[t]{2}{*}{ precip2 } & & & & & & & 0.166 \\
\hline & & & & & & & $(0.392)$ \\
\hline _cons & 19015.0 & 22449.0 & -14968.3 & -20940.4 & $-33057.1^{* *}$ & $-117505.9 * *$ & 209995.9 \\
\hline & $(0.095)$ & $(0.063)$ & $(0.084)$ & $(0.064)$ & $(0.007)$ & $(0.007)$ & $(0.822)$ \\
\hline $\mathrm{N}$ & 1032 & 1032 & 1032 & 1032 & 1032 & 942 & 938 \\
\hline chi2 & 52927.2 & 66336.6 & 62714.3 & 58363.0 & 99587.7 & 261365.8 & 168112.8 \\
\hline$p$-values in pare & theses & & & & & & \\
\hline${ }^{*} p<0.05$ & ${ }^{* *} p<0.01$ & $* * * p<0.001$ & & & & & \\
\hline
\end{tabular}

Table 2: Estimations' results 


\begin{tabular}{|c|c|c|c|c|c|c|c|}
\hline Tests & model 1 & model 2 & model 3 & model 4 & model 5 & model 6 & model 7 \\
\hline $\begin{array}{l}\text { Arellano-Bond test of } \\
\text { second-order serial } \\
\text { correlation }\end{array}$ & $\begin{array}{c}z=1.11 \\
(p=0.267)\end{array}$ & $\begin{array}{c}z=-1.26 \\
(p=0.206)\end{array}$ & $\begin{array}{c}z=-0.92 \\
(p=0.360)\end{array}$ & $\begin{array}{c}z=-0.85 \\
(p=0.398)\end{array}$ & $\begin{array}{c}z=-0.92 \\
(p=0.360)\end{array}$ & $\begin{array}{c}z=-0.10 \\
(p=0.917)\end{array}$ & $\begin{array}{c}z=-0.33 \\
(p=0.744)\end{array}$ \\
\hline
\end{tabular}

Table 3: Second-order auto-correlation test

in the Legal Amazon MCAs. Since our main hypothesis is that the effect of sugarcane expansion is indirect, i.e. materializes through a displacement of ranching activities, it is perhaps unsurprising that the coefficients associated with the sugarcane variable are mostly insignificant. We nevertheless retain these regressors in the specifications so that the interaction terms can be plausibly interpreted.

Regarding the coefficients associated with the interaction terms, we observe that they are small and significant and remain so in most specifications even after the introduction of additional control variables. These interaction effects imply that the role played by cattle heads in forest conversion is sensitive to the levels of sugarcane acreage in the state of São Paulo. In other words, they express the share of cattle's effect on deforestation that is indirectly due to the expansion of sugarcane acreage. ${ }^{18}$ They furthermore suggest that had there been no sugarcane production in São Paulo state then cattle ranching would have had a smaller impact on land clearing in the Amazon. To further investigate this, we computed both the long-run and the short-run marginal effects of cattle on cleared land. ${ }^{19}$ Table 4 provides the results.

In model 2, only the cattle variable is included for both the long- and short-run computations. From model 5 on, the difference between the long- and the short-run marginal effect is clearly visible. Indeed, taking into account the coefficients associated with the interaction terms between cattle and current and lagged values of sugarcane acreage in São Paulo increases the magnitude of the effect of cattle on forest conversion. For instance, when considering model 6 - our reference model - one can see that the short-run marginal effect of cattle is 2.53 hectares of cleared land per additional unit of livestock. In the long-run, when accounting for the displacement effect, this increases to 4.63 cleared hectares per additional cattle head. These long-run marginal effects may

\footnotetext{
${ }^{18} \mathrm{~A}$ similar interpretation of interaction terms' coefficients can be found in Borensztein et al. (1998) and Sandar Kyaw and Macdonald (2009), where the authors investigate the channels through which capital flows affect economic growth.

${ }^{19}$ Assuming a model of the kind $y_{t}=\alpha_{1} y_{t-1}+\alpha_{2} y_{t-2}+\beta_{1} X_{t}+\beta_{2} X_{t-1}+\delta_{1} X_{t} Z_{t}+\delta_{2} X_{t} Z_{t-1}+u_{t}$. Then, the marginal long-run effect of $X$ on $y$ is given by $\left(\beta_{1}+\beta_{2}+\delta_{1} \bar{Z}+\delta_{2} \bar{Z}\right) /\left(1-\alpha_{1}-\alpha_{2}\right)$, where $\bar{Z}$ is the mean of $Z$ across all observations and all years. In the same vein, the short-run marginal effect of $X$ on $y$ is given by $\left(\beta_{1}\right) /\left(1-\alpha_{1}-\alpha_{2}\right)$.
} 


\begin{tabular}{lccccccc}
\hline \hline & model 1 & model 2 & model 3 & model 4 & model 5 & model 6 & model 7 \\
\hline Short-run effect & - & $1.90(p=0.00)$ & - & - & $3.52(p=0.00)$ & $2.53(p=0.00)$ & $2.21(p=0.00)$ \\
Long-run effect & - & $1.90(p=0.00)$ & - & - & $6.87(p=0.00)$ & $4.63(p=0.00)$ & $4.09(p=0.00)$ \\
\hline \hline
\end{tabular}

Table 4: Marginal effects of cattle on cleared land

seem very high at the first sight. However, they are consistent with the more extensive ranching methods in the Brazilian Amazon compared to those observed in São Paulo state since 1970 (See Table D.1 in Appendix D).

Finally, two additional remarks should be made regarding the results. First, the coefficient of the interaction between cattle heads and sugarcane acreage lagged twice is significant and stable irrespective of the specification considered. Given the distance between the main sugarcane production areas in Brazil and the Amazon frontier, this provides evidence for a consistent displacement effect but one that only materializes after a 10 to 15 -year period. ${ }^{20}$ Second, in model 7 we added agricultural GDP in São Paulo and average annual precipitations (normal and squared values) as control variables. The measure of agricultural GDP is included to control for the fact that the expansion of sugarcane could be proxying for general growth of agriculture in this area, which we expect would also tend to push cattle ranching towards the forest frontier. The inclusion of these additional explanatory variables does not affect the main results of the regression analysis, which tends to confirm their robustness.

\subsection{The traditional deforestation drivers}

We include in the regression analysis factors that have been identified in the literature as key drivers of deforestation in the Brazilian Amazon. These are hectares allocated to soy and pasture (both natural and planted), road density, average amount of credit allocated to farmers, soil fertility, population density, GDP per capita and distance to the state capital (which can be interpreted as a proxy for access to markets). In general, all of these factors are expected to exhibit a positive relationship with cleared land except for distance to the state capital, which is expected to have a negative relationship with cleared land. As shown in Table 2, whenever significant, the coefficients associated with these regressors present the expected sign and are therefore in line with previous studies

\footnotetext{
${ }^{20}$ Higher lags of sugarcane acreage were also included in the interaction terms but were not shown to have any significant impact on cleared land.
} 
(e.g. Pfaff, 1999; Andersen et al. 2002).

\section{Conclusion}

In this paper, we investigated indirect land-use changes induced by sugarcane expansion in Brazil. A link is demonstrated between this expansion, occurring in the Center-South areas of the country, and forest conversion in the Legal Amazon, located much further north. Indeed, our results suggest a displacement of at least some cattle ranching activities towards the forest frontier subsequent to the increase in sugarcane acreage. This effect is shown to be dynamic with 10 to 15 years passing before it materializes. Our results thus suggest that cattle ranching activities move gradually between non-forest and forest regions. Additionally, we were able to disentangle the indirect effect of displacement on forest conversion from the direct impact of cattle ranching in the Amazon. Although relatively small compared to the effect of the traditional deforestation drivers the indirect effect imputable to displacement is statistically significant, which is shown when computing the long-run marginal effect of cattle ranching on forest conversion.

Since sugarcane is used as an energy crop for ethanol production in Brazil, these results call into question the desirability of ethanol as an oil substitute. Under the assumption of no land-use change in supplying the biofuel feedstock, Gallagher (2008) demonstrates that the best greenhouse gas savings from ethanol, compared to gasoline, can be achieved from sugarcane produced in Brazil. ${ }^{21}$ But as shown by Lapola et al. (2010), these savings begin to dissipate once the indirect effect on forest conversion is taken into account. We note, however, that their results are based on assumed and not observed parameter values. Given the abundance of land in Brazil, the effect calibrated by Lapola et al. (2010) may not be as severe as has been assumed. In other words, the displacement effect may have been overstated, at least for the expansion of sugarcane production. While the estimation of the carbon balance of ethanol production in Brazil is beyond the scope of the present paper, our results can be used to give more empirical weight to the design of future policies to promote biofuels.

Irrespective of the relative size of the displacement effect for forest conversion behavior, it is clear that future policies should ensure that the expansion of sugarcane takes place on idle land rather than land currently utilized by high-value agricultural commodities. In other words, further incentives to clear forest via the displacement of such commodities, including beef and soybean, should be removed. Note that given the 10-15 year period

\footnotetext{
${ }^{21}$ Note that this result depends on sugarcane yields and whether or not bagasse is utilized for heat and power (Gallagher, 2008).
} 
for displacement to materialize, long-term monitoring of policy impacts would be necessary. Investments in research aiming at increasing sugarcane productivity should also be encouraged. The Brazilian Agriculture Research Corporation (EMBRAPA) continues to undertake work in this direction. Similarly, the intensification of cattle ranching at the forest frontier could help mitigate the displacement effect. Of course, if sugarcane is to be expanded in the São Paulo region it is possible that there is much less cattle ranching and soybean production concentrated there than in the past thus reducing future opportunities for displacement.

The Brazilian government has plans to further expand its sugarcane/ethanol sector, in part to meet a projected rise in international demand for ethanol. However, the growing body of evidence for indirect land-use changes, in particular those that may induce higher levels of deforestation, challenge the received wisdom about the environmental benefits of ethanol production. With Brazil also fully engaged in putting into place various mechanisms that aim at reducing emissions from deforestation and forest degradation (REDD), it is also imperative that the displacement of agricultural production to Amazon is accounted for. If REDD is implemented at a wider scale in Brazil, for example, via national-level policies that reduce the returns from agricultural production at the forest frontier then it might help slow down deforestation. In this case, there may be potential to counter displacement effects. But on the other hand, if REDD is implemented via incentive payments to cattle ranchers at the frontier, the higher prices that drive displacement may increase REDD policy costs. Either way, any indirect land-use changes need to be explicitly taken into account in REDD baseline calculations. The results presented in this paper are a first step in accurately estimating the potential size of these effects.

\section{References}

Andersen, L.E., C.W.J. Granger, E. Reis, D.Weinhold and S. Wunder (2002) The Dynamics of Deforestation and Economic Growth in the Brazilian Amazon, Cambridge University Press

Andrade de Sá, S., C. Palmer and S. Engel (2012) "Ethanol, Food and Forests" Environmental and Resource Economics 51: 1-21

Angelsen, A. (2007) "Forest Cover Change in Space and Time: Combining the von Thünen and Forest Transition Theories" World Bank Working Paper Series, Washington D.C.

Angelsen, A. and D. Kaimowitz (1999) "Rethinking the Causes of Deforestation: Lessons from Economic Models" World Bank Research Observer 14: 73-98 
Anselin, L. (2009) "Thirty Years of Spatial Econometrics" Papers in Regional Science 89: $3-25$

Arellano, M. and S. Bond (1991) "Some Tests of Specification for Panel Data: Monte Carlo Evidence and an Application to Employment Equations" Review of Economic Studies 58: 277-297

Arellano, M. and O. Bover (1995) "Another Look at the Instrumental Variable Estimation of Error-Components Models" Journal of Econometrics 68: 29-51

Arima, E. Y., P. Richards, R. Walker, and M. M. Caldas (2011) "Statistical Confirmation of Indirect Land Use Change in the Amazon" Environmental Research Letters 6: $1-7$.

Barbier, E.B. and J.C. Burgess (2001) "The Economics of Tropical Deforestation" Journal of Economic Surveys 15: 413-421

Barona, E., N. Ramankutty, G. Hyman and O.T. Coomes (2010) "The Role of Pasture and Soybean in Deforestation of the Brazilian Amazon" Environmental Research Letters 5: 024002

Blundell, R. and S. Bond (1998) "Initial Conditions and Moment Restrictions in Dynamic Panel Models" Journal of Econometrics 87: 115-143

Borensztein, E., J. De Gregorio and J.W. Lee (1998) "How does Foreign Direct Investment Affect Economic Growth" Journal of International Economics 45: 115-135

Cameron, A.C, and P.K. Trivedi (2009) Microeconometrics using Stata Stata Press, College Station, Texas

Chomitz, K.M. and T.S. Thomas (2003) "Determinants of Land Use in Amazonia: A Fine-Scale Analysis" American Journal of Agricultural Economics 85: 1016-1028

EMBRAPA - Brazilian Agriculture Research Corportation (2009) "Zoneamento Agroecológico da Cana-de-açucar", Rio de Janeiro

FAO - Food and Agriculture Organization of the United Nations (2010) "Global Forest Resources Assessment" FAO Forestry Paper 163, Rome

Feng, H., O.D. Rubin and B.A. Babcock (2010) "Greenhouse Gas Impacts of Ethanol from Iowa corn: Life Cycle Assessment versus System Wide Approach" Biomass and Bioenergy 34: 912-921

Gallagher, E. (2008) The Gallagher Review of the Indirect Effects of Biofuel Production, Renewable Fuels Agency, London. 6

Goldemberg, J. (2008) "The Brazilian Biofuel Industry" Biotechnology for Biofuels 1: 
Goldemberg, J. and P. Guardabassi (2009) "Are Biofuels a Feasible Option?" Energy Policy 37: 10-14

Kaimowitz, D. and A. Angelsen (1998) Economic Models of Tropical Deforestation: A Review, CIFOR-Indonesia

Lapola, D. M., R. Schaldach, J. Alcamo, A. Bondeau, J. Koch, C. Koelking, and J. A. Priess (2010) "Indirect Land-Use Changes Can Overcome Carbon Savings from Biofuels in Brazil" Proceedings of the National Academy of Sciences 107: 3388-3393.

MAPA - Ministry of Agriculture, Livestock and Food Supply (2009) "Anuário Estatistico da AgroEnergia", Brasilia

MAPA - Ministry of Agriculture, Livestock and Food Supply (2010) "Anuário Estatistico da AgroEnergia", Brasilia

Margulis, S. (2004) "Causes of Deforestation of the Brazilian Amazon" World Bank Working Paper Series, Washington D.C.

Nassar, A.M., B.F.T, Ruddorf, L.B. Antoniazzi, D. Alvesde Aguiar, M.R.P. Bacchi and M. Adami (2008) "Prospects of the Sugarcane Expansion in Brazil: Impacts on Direct and Indirect Land Use Changes" in Zuurbier, P. and J. van de Vooren (Eds.) Sugarcane Ethanol: Contributions to Climate Change Mitigation and the Environment, Wageningen Academic Publishers

Pfaff, A. (1999) "What Drives Deforestation in the Brazilian Amazon? Evidence from Satellite and Socioeconomic Data" Journal of Environmental Economics and Management 37(1): $26-43$.

Righelato, R. and D.V: Spracklen (2007) "Carbon Mitigation by Biofuels or by Saving and Restoring Forests?" Science 317: 902

Rudel, T.K. (2005) Tropical Forests: Regional Paths of Destruction and Regeneration in the Late Twentieth Century, Columbia University Press, New York.

Sandar Kyaw, K. and R. Macdonald (2009) "Capital Flows and Growth in Developing Countries: A Dynamic Panel Data Analysis" Oxford Development Studies 37: 101-122

Searchinger, T., R. Heimlich, R.A. Houghton, F. Dong, A. Elobeid, J. Fabiosa, S. Tokgoz, D. HAyes and T. Yu (2008) "Use of U.S. Croplands for Biofuels Increases Greenhouse Gases Through Emissions from Land-Use Changes" Science 319: 1238-1240

de Souza Ferreira Filho, J.B. and M. Horridge (2011) "Ethanol Expansion and Land Use Change in Brazil" Center of Policy Studies Working Paper No. G-218

StataCorp (2009) Stata Statistical Software: Release 11. College Station, TX: StataCorp LP. 
Tilman, D., R. Socolow, J.A. Foley, J. Hill, E. Larson, L. Lynd, S. Pacala, J. Reilly, T. Searchinger, C. Somerville and R. Williams (2009) "Beneficial Biofuels - The Food, Energy and Environment Trilemma" Science 325: 270-271

Weinhold, D. and E. Reis (2008) "Transportation Costs and the Spatial Distribution of Land Use in the Brazilian Amazon" Global Environmental Change 18: 54-68

Windmeijer, F. (2005) "A Finite Sample Correction for the Variance of Linear Efficient Two-Step GMM Estimators" Journal of Econometrics 126: 25-51

World Bank (2011) Rising Global Interest in Farmland: Can it Yield Sustainable and Equitable Benefits? World Bank, Washington DC.

Zuurbier, P. and J. van de Vooren (Eds) (2008) Sugarcane Ethanol: Contributions to Climate Change Mitigation and the Environment, Wageningen Academic Publishers 


\section{Appendices}

A Main sugarcane production areas in Brazil

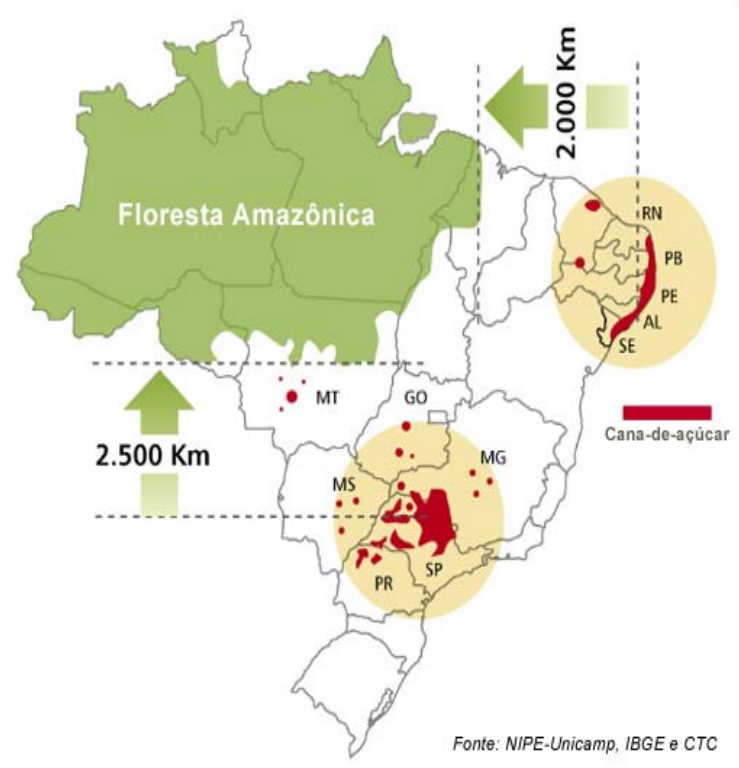

Figure A.1: Main sugarcane production areas in Brazil 


\section{B Variables description}

\begin{tabular}{|c|c|c|}
\hline Variable & Definition & Source \\
\hline cleared & Hectares of land cleared & $\begin{array}{l}\text { IBGE - Agricultural } \\
\text { Census }\end{array}$ \\
\hline cattle & Cattle heads & $\begin{array}{l}\text { IBGE - Agricultural } \\
\text { Census }\end{array}$ \\
\hline SPsgen & $\begin{array}{l}\text { Hectares of land under sugarcane in São } \\
\text { Paulo state }\end{array}$ & $\begin{array}{l}\text { IBGE - Agricultural } \\
\text { Census }\end{array}$ \\
\hline soya & Hectares of land under soy & $\begin{array}{l}\text { IBGE - Agricultural } \\
\text { Census }\end{array}$ \\
\hline natpast & Hectares of natural pasture & $\begin{array}{l}\text { IBGE - Agricultural } \\
\text { Census }\end{array}$ \\
\hline plpast & Hectares of planted pasture & $\begin{array}{l}\text { IBGE - Agricultural } \\
\text { Census }\end{array}$ \\
\hline gdpcap & GDP per capita ( $R \$$ of 2000$)$ & IPEAdata \\
\hline pop_dens & $\begin{array}{l}\text { Population density (Total MCA } \\
\text { population/MCA area) }\end{array}$ & IPEAdata \\
\hline road_dens & $\begin{array}{l}\text { Road density ( } \mathrm{km} \text { of road within MCA/MCA } \\
\text { area) }\end{array}$ & IPEAdata \\
\hline credit & $\begin{array}{l}\text { Average credit allocated to rural } \\
\text { establishments ( } R \$ \text { of } 2000)\end{array}$ & IPEAdata \\
\hline dist_state_cap & $\begin{array}{l}\text { Average distance from counties' capital } \\
\text { (within a given MCA) to the state capital in } \\
\mathrm{km}\end{array}$ & IPEAdata \\
\hline gdpagric_SP & $\begin{array}{l}\text { Value added of agricultural activities in São } \\
\text { Paulo (R\$ of 2000) }\end{array}$ & IPEAdata \\
\hline fertility & $\begin{array}{l}\text { Categorial variable. } 1=\text { very low, } 2=\text { low, } \\
3=\text { medium, } 4=\text { medium/high, } 5=\text { high }\end{array}$ & GIS \\
\hline precip & Average yearly precipitations in milliliters & IPEAdata \\
\hline precip2 & Squared precipitations & Own construction \\
\hline
\end{tabular}

Table B.1: Main variables description 


\section{Descriptive statistics}

\begin{tabular}{lclrr}
\hline \hline \multicolumn{1}{c}{ Variables } & Mean & Max & Min & \multicolumn{1}{c}{ sd } \\
\hline cleared & 39957.71 & 9286486 & 0 & 159668.8 \\
cattle & 34178.45 & 8016933 & 0 & 138857.3 \\
SPsgcn & 1671501 & 3498240 & 524139 & 1051666 \\
soya & 2405.178 & 2322290 & 0 & 26987.38 \\
natpast & 27596.94 & 4594066 & 0 & 118775.4 \\
plpast & 18489.19 & 5404859 & 0 & 109588.4 \\
gdpcap & 3485.831 & 823211.5 & 0 & 10832.85 \\
pop_dens & 98.32099 & 201954.5 & 0 & 1468.494 \\
road_dens & 0.463128 & 1.309967 & 0.0012848 & 0.23718 \\
credit & $1.01 \mathrm{E}+10$ & $4.72 \mathrm{E}+12$ & 0 & $7.60 \mathrm{E}+10$ \\
dist_state_cap & 249.1717 & 1476 & 0 & 150.8784 \\
dist_SP & 2163.463 & 3276.536 & 1064.16 & 520.2614 \\
gdpagric_SP & $1.10 \mathrm{E}+07$ & $1.72 \mathrm{E}+07$ & 6439376 & 3584624 \\
fertility & 1.974518 & 5 & 1 & 0.9433757 \\
precip & 1332.686 & 3389 & 346 & 423.875 \\
\hline \hline
\end{tabular}

Table C.1: Descriptive statistics of main variables 


\section{Cattle stocking density in different regions of Brazil}

\begin{tabular}{lcccccc}
\hline Region & $\mathbf{1 9 7 0}$ & $\mathbf{1 9 7 5}$ & $\mathbf{1 9 8 0}$ & $\mathbf{1 9 8 5}$ & $\mathbf{1 9 9 6}$ & $\mathbf{2 0 0 6}$ \\
\hline Sao Paulo & 1.00 & 1.00 & 1.15 & 1.13 & 1.41 & 1.85 \\
Legal Amazon & 0.27 & 0.31 & 0.39 & 0.44 & 0.74 & 1.04 \\
Cerrado & 0.44 & 0.56 & 0.62 & 0.69 & 0.83 & 0.96 \\
\hline
\end{tabular}

Table D.1: Cattle density (cattle heads/ha) 